\title{
CRITIQUE ON THE COUCH
}

New Directions in Critical Theory 


\section{New Directions in Critical Theory Amy Allen, General Editor}

New Directions in Critical Theory presents outstanding classic and contemporary texts in the tradition of critical social theory, broadly construed. The series aims to renew and advance the program of critical social theory, with a particular focus on theorizing contemporary struggles around gender, race, sexuality, class, and globalization and their complex interconnections.

For a complete list of titles, see page 267. 


\section{CRITIQUE ON THE COUCH

\author{
Why Critical Theory \\ Needs Psychoanalysis
}

\section{Amy Allen}

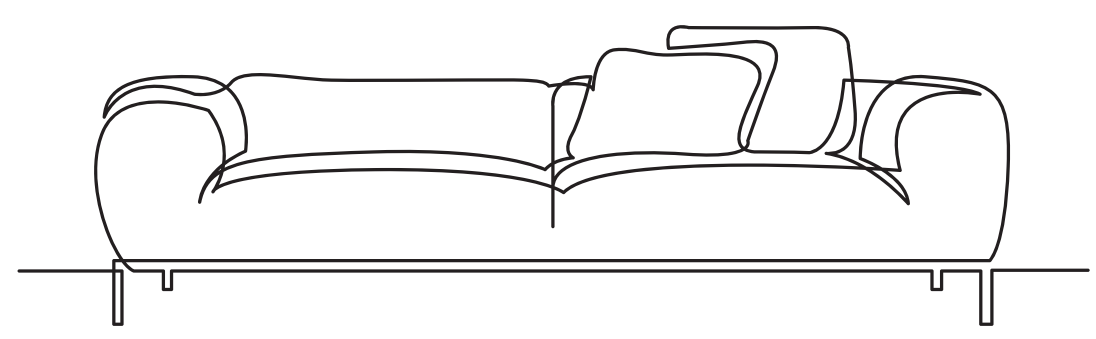

Columbia University Press

New York 


\author{
* \\ Columbia University Press \\ Publishers Since 1893 \\ New York Chichester, West Sussex \\ cup.columbia.edu \\ Copyright $\odot 2021$ Columbia University Press \\ All rights reserved
}

\section{Library of Congress Cataloging-in-Publication Data}

Names: Allen, Amy, author.

Title: Critique on the couch : why critical theory needs psychoanalysis / Amy Allen.

Description: New York : Columbia University Press, 2020. | Series: New directions in critical theory | Includes bibliographical references and index.

Identifiers: LCCN 2020020823 (print) | LCCN 2020020824 (ebook) | ISBN 9780231198608

(hardback) | ISBN 9780231198615 (trade paperback) | ISBN 9780231552714 (ebook)

Subjects: LCSH: Psychoanalysis-Political aspects. | Critical theory.

Classification: LCC BF175.4.S65 A55 2020 (print) | LCC BF175.4.S65 (ebook) |

DDC $150.19 / 5-\mathrm{dc} 23$

LC record available at https://lccn.loc.gov/2020020823

LC ebook record available at https://lccn.loc.gov/2020020824

Columbia University Press books are printed on permanent and durable acid-free paper.

Printed in the United States of America

Cover design: Lisa Hamm

Cover image: Digital composite 